\title{
Kinetic Study on the Preparation of Aluminum Fluoride Based on Fluosilicic Acid
}

\author{
Gaoxiang Chen', Xingdong Yang1, Jiyan Qu', Jianhong Luo ${ }^{1, *}$, Zhiye Zhang1, Lan Sun,"* \\ ${ }^{1}$ Department of Chemical Engineering, Sichuan University, Chengdu, Sichuan 610065, P.R. China. \\ ${ }^{2}$ Department of Mechanical Engineering, Sichuan University, Chengdu, Sichuan 610065, P.R. China. \\ "Corresponding authors: e-mail: luojianhong@scu.edu.cn, sunlan@scu.edu.cn
}

\begin{abstract}
Reasonable mathematical derivation and mechanism model in the process of producing aluminum fluoride by fluosilicic acid is the key to the industrial treatment of fluorine resources in the tail gas of phosphate ore. In this work, aluminum fluoride was generated directly by fluosilicic acid to extract fluorine from the tail gas of phosphate rock. The uncreated-core model dominated by interfacial reaction and the uncreated-core model dominated by internal diffusion-reaction were then respectively utilized to describe the reaction kinetics of the generation of aluminum fluoride. The result showed that the uncreated-core model was dominated by interface reaction and internal diffusion, the apparent reaction order $\mathrm{n}=1$, and the activation energy $\mathrm{E}_{\mathrm{a}}=30.8632 \mathrm{~kJ} \cdot \mathrm{mol}^{-1}$. Product characterization and kinetic analysis were employed to deduce the reaction mechanism of preparing aluminum fluoride. The theoretical basis for the low-cost recycling of fluorine resources in the tail gas of industrial phosphate ore was provided in this work.
\end{abstract}

Keywords: kinetic study, fluosilicic acid, aluminum fluoride, uncreated-core model.

\section{INTRODUCTION}

The recovery and reuse of fluorine in the tail gas of phosphate ore are one of the key technologies to realize environmentally friendly phosphorus chemical industry ${ }^{1,2}$. As a typical product, aluminum fluoride is widely used in the electrolytic aluminum industry ${ }^{3,4}$. The production methods of aluminum fluoride mainly included three kinds of fluorite as the main raw material: wet method, dry method, non-water method and fluosilicic acid as the main raw material: ammonia method, direct method, monohydrate method ${ }^{5,6,7}$. At present, with the decrease of fluorite reserves, the production of aluminum fluoride from fluorite as the main raw material was no longer advantageous in terms of cost and production ${ }^{8}$. Among the three methods using fluosilicic acid as the main raw material, the direct reaction method has gained the favor of industry for the low cost and simple operation process $^{6}$. As the main raw material of wetprocess phosphoric acid in China's phosphorus chemical industry, phosphate ores containing 3-5\% fluorine have attracted extensive attention in the fluorine chemical industry. In the process of wet-process phosphoric acid, fluorine was mainly spilled out in the form of fluorinecontaining gas and was transferred to fluosilicic acid by water absorption, ${ }^{9}$. Therefore, the effective recovery of fluorine from the tail gas of wet process phosphoric acid was a problem concerned by industry. In addition, there were phase transition and contamination problems in the direct method using fluosilicic acid as a fluorine source, the purity and bulk density of aluminum fluoride was a major challenge ${ }^{11,12}$.

Fluosilicic acid was used to react directly with aluminum hydroxide in the process of producing aluminum fluoride by the direct method. However, this reaction was a three-step reaction rather than a one-step reaction. Step 1: Fluosilicic acid neutralized aluminum hydroxide to produce aluminum fluosilicic acid and water. Step 2: Aluminum fluosilicate acid was hydrolyzed to produce aluminum fluoride, silicon dioxide and hydrogen fluoride. Step 3: In the second step, the product hydrogen fluoride and unreacted aluminum hydroxide undergo acid-base neutralization reaction to produce aluminum fluoride and water. The reaction equations were as follows ${ }^{13}$ :

$$
\begin{aligned}
& 3 \mathrm{H}_{2} \mathrm{SiF}_{6}+2 \mathrm{Al}(\mathrm{OH})_{3} \stackrel{k_{1}}{\longrightarrow} \mathrm{Al}_{2}\left(\mathrm{SiF}_{6}\right)_{3}+6 \mathrm{H}_{2} \mathrm{O} \\
& \mathrm{Al}_{2}\left(\mathrm{SiF}_{6}\right)_{3}+6 \mathrm{H}_{2} \mathrm{O} \stackrel{k_{2}}{\longrightarrow} 2 \mathrm{AlF}_{3}+3 \mathrm{SiO}_{2} \downarrow+12 \mathrm{HF} \\
& 3 \mathrm{HF}+\mathrm{Al}(\mathrm{OH})_{3} \stackrel{k_{3}}{\longrightarrow} \mathrm{AlF}_{3}+3 \mathrm{H}_{2} \mathrm{O}
\end{aligned}
$$

Previous studies ${ }^{14,15,16}$ on the direct preparation of aluminum fluoride by fluosilicic acid have focused on improving the stability of silica precipitation to facilitate the rapid separation of silica before the crystallization of aluminum fluoride to improve the purity of products. For instance, Babyat. $\mathrm{M}$ et al. ${ }^{17}$ took the filtration rate of silicon dioxide as the index and studied the effects of fluosilicic acid concentration, temperature, the addition of aluminum hydroxide, stirring speed and reaction time. Meanwhile, combined with scanning electron microscopy, the mechanism hypothesis of the direct preparation of aluminum fluoride by fluosilicic acid was proposed. Researchers found that silica adsorbed on the surface of aluminum hydroxide and formed clusters. Krysztafkiewicz A. et al. ${ }^{12}$ improved the purity of the product by adding washing steps after the initial filtration of silica and aluminum fluoride. Researchers found that placing the filtered silica in water at 80 degrees Celsius for secondary washing, or in hydrochloric acid at a 20 percent mass concentration, produced good results for both.

However, there were few reports on the reaction kinetics and mechanism of aluminum fluoride prepared by direct method ${ }^{18}$. The direct method was a liquid-solid reaction, and its macroscopic reaction rate was not only influenced by the interface reaction, but also by the process of external and internal diffusion ${ }^{19,20}$. In this work, based on the shooting of scanning electron microscope, a reasonable mathematical model was provided to deduce the reaction process, and the mechanism of the direct method for the preparation of aluminum fluoride was revealed by combining the reaction kinetics and experimental data. This work not only provided a theoretical basis for the realization of low-cost recovery of fluorine 
resources in the tail gas treatment of phosphate rock but also provided theoretical guidance for the effective separation of silica and aluminum fluoride. Meanwhile, this experiment predicted the influence of different process conditions on the experimental results and tested the applicability of the process in actual production.

\section{EXPERIMENTS}

\section{Materials and analysis}

In this study, chemical pure grade fluosilicic acid was used as raw material due to the mechanism study. Fluosilicic acid was used as a reactant produced by Chengdu Kelong Chemical Co., Ltd (China; CP grade; Mass concentration: $34.69 \%$ ). Aluminium hydroxide was used as a reactant produced by Chengdu Jinshan Chemical Co., Ltd (China; AR grade). Deionized water was used in all experiments. The other provided reagents included sodium hydroxide, potassium hydroxide, nitric acid, hydrochloric acid, potassium chloride, phenolphthalein and anhydrous ethanol were of the analytical grades.

The content of silica in the sample was determined by potassium fluosilicate volumetric method ${ }^{21}$. The mass concentration of the fluosilicic acid solution was determined by the potassium fluosilicic acid method ${ }^{22}$. The field emission scanning electron microscope (JSM-7500 F, Japan Electron Optics Laboratory Co., Ltd.) was used to observe the morphology and microstructure of the samples.

\section{Equipment and Procedure.}

The experimental process was shown in Figure 1. The fluosilicic acid solution was diluted by deionized water to a certain concentration and preheated in a reactor of the one-liter volume. The temperature in the reactor was controlled by an electronic constant temperature water bath pot (601, JiangSu Jinyi Instrument Technology Co., Ltd.), and the real-time temperature display in the reaction was read by a mercury thermometer. The diameter of PTFE agitator was $60.0 \mathrm{~mm}$. The quantitative aluminum hydroxide was added to the reaction kettle with a certain drop acceleration $(0.216 \mathrm{~g} / \mathrm{s})$. After the reactant

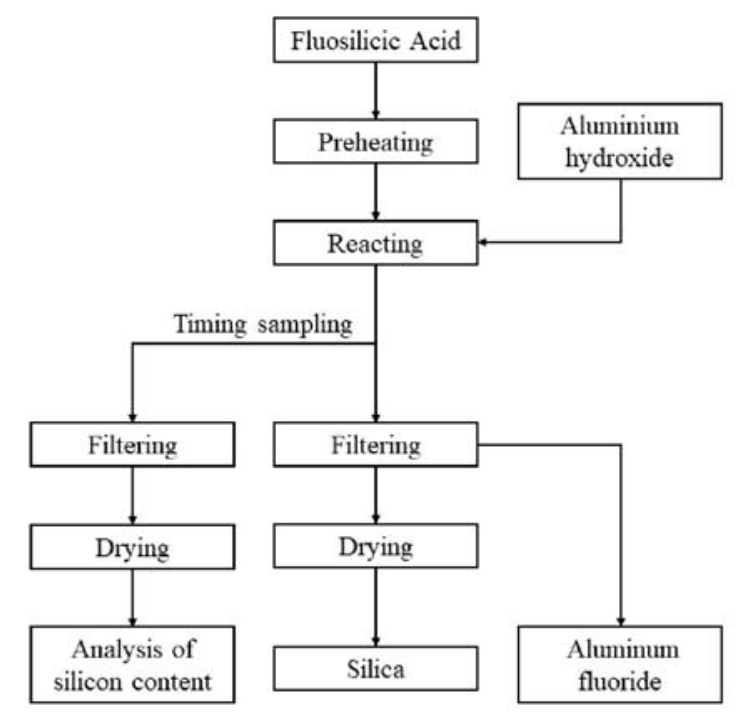

Figure 1. Flowchart of the mechanism of the direct preparation of aluminum fluoride by fluosilicic acid has been added, the stirring speed was set to $400 \mathrm{rpm}$ by a digital display electric mixer and the reaction began. During the reaction process, a small amount of reaction liquid was taken out with $10 \mathrm{~mL}$ plastic dropper every 5 minutes, and the reaction liquid was quickly filtered by the vacuum filter extractor. The filter residue was placed in the electric oven at $80^{\circ} \mathrm{C}$ and dried until the mass was constant. After drying, remove the filter residue and put it into the atmospheric dryer to analyze the silica content in the filter residue. The total reaction time was set to 30 minutes. After the reaction, the reaction liquid was rapidly filtered. The filtrate was put into the electronic constant temperature water bath pot to be evaporated and crystallized. After filtration, the filter residue was placed in the electric oven at $80{ }^{\circ} \mathrm{C}$ and dried until the mass was constant.

The experimental conditions adopted in this work were described in Table 1.

Table 1. Various experimental conditions of reaction

\begin{tabular}{|c|c|}
\hline Experimental condition & Value \\
\hline Reaction temperature $\left({ }^{\circ} \mathrm{C}\right)$ & $75-95$ \\
\hline $\begin{array}{c}\text { The mass concentration of fluosilicic } \\
\text { acid }(\%)\end{array}$ & 15.5747 \\
\hline $\mathrm{n}\left(\mathrm{Al}(\mathrm{OH})_{3}\right): \mathrm{n}\left(\mathrm{H}_{2} \mathrm{SiF}_{6}\right)$ & 1.7 \\
\hline Stirring speed $(\mathrm{rpm})$ & 400 \\
\hline Reaction time (min) & 30 \\
\hline
\end{tabular}

\section{RESULTS AND DISCUSSION}

\section{Characteristic analysis of the product.}

The Eqs.(1)-(3) of fluosilicic acid and aluminum hydroxide showed that the reaction was a heterogeneous liquid-solid reaction. SEM characterization of products at different periods during the reaction process was shown in Figure 2. It could be seen that the morphology of the aluminum hydroxide was a mainly dense flake, while the morphology of the silicon dioxide was mainly fine particles. With the increase of reaction time, the agglomeration of the silica became more obvious. Aluminum hydroxide was the main matrix of silica dispersion. Babyat. $\mathrm{M}$ et al. ${ }^{17}$ also observed this phenomenon and speculated that the mechanism model of this reaction could be explained by the uncreated-core model of the reaction. Aluminum hydroxide was considered to have insufficient internal voids for external fluids to easily diffuse into aluminum hydroxide, thus the uncreated-core model was superior to the homogeneous model.

From the SEM diagram, we can also observe the formation of product clusters. Silica microspheres were formed on the aluminum hydroxide flake surface in a reaction time of only 5 minutes. This indicated that fluorosilicic acid was diffused to aluminum hydroxide surface to produce aluminum fluorosilicic acid, aluminum fluorosilicic acid quickly hydrolyzed to silicon dioxide. After the reaction time of 10 minutes, silica microspheres gathered to form clusters, and the clusters attached to the surface of aluminum hydroxide gradually grew larger with the increase of time, which can be understood as the growth of silica product layer attached to the surface of aluminum hydroxide. The cluster structure may be caused 

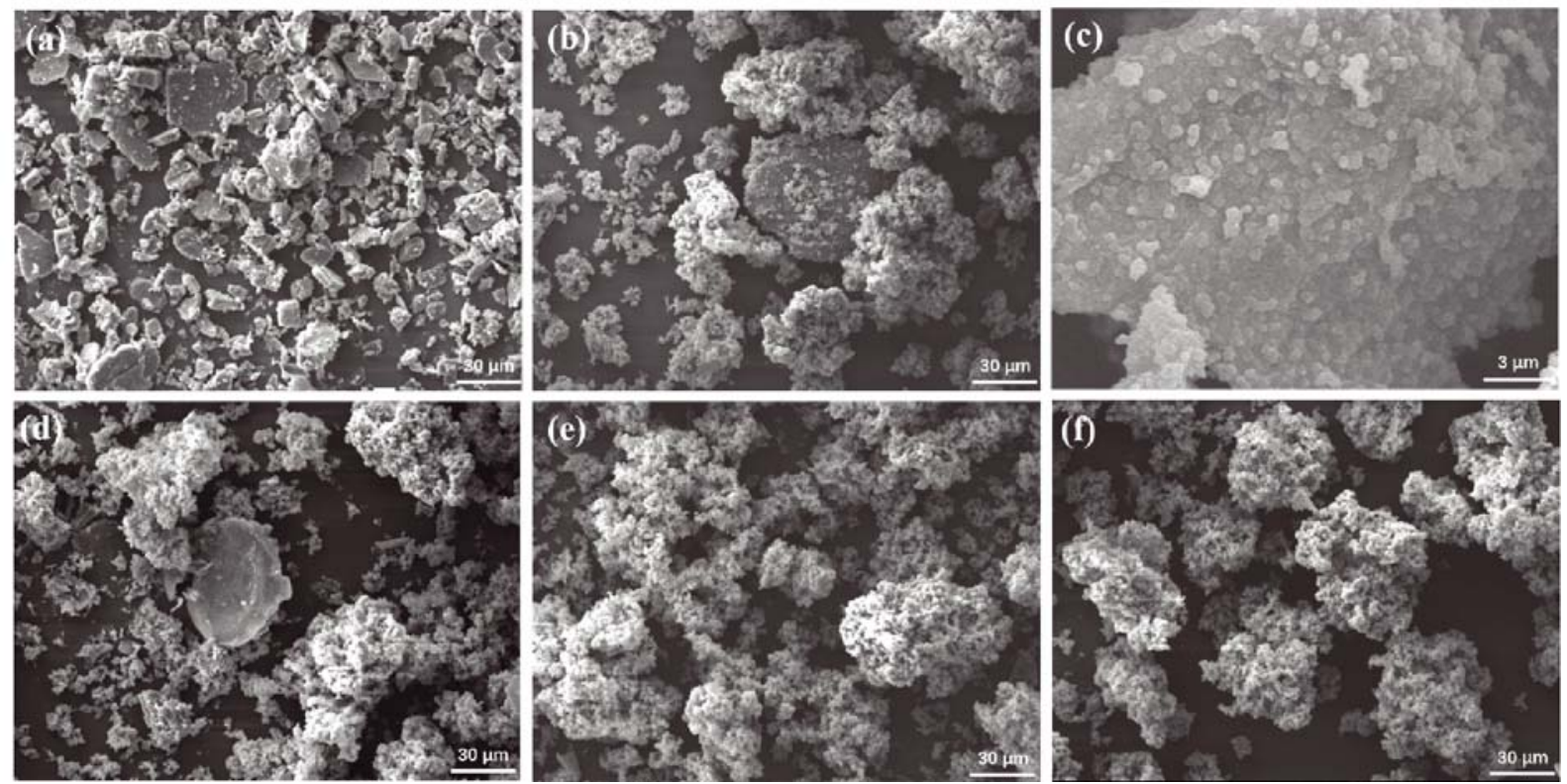

Figure 2. SEM characterization of the reaction products at different time. a: The solid reactants before the reaction started. b: The solid products at 5 minutes. c: The solid products at 5 minutes. d: The solid products at 10 minutes. e: The solid products at 20 minutes. f: The solid products at 30 minutes

by the intense agitation that caused silica microspheres to aggregate in the aqueous medium.

\section{Kinetic formula for the formation of silica}

\section{Intrinsic reaction kinetics}

According to the Eqs. (1)-(3), the reaction is a consecutive reaction. $k_{1}, k_{2}$ and $k_{3}$ are defined as the reaction rate constants of Eq. (1), Eq. (2) and Eq. (3), respectively. Considering that Eq. (1) and Eq. (3) were part of the acid-base neutralization reaction, the reaction rate was higher than that of Eq. (2). Thus, Eq. (2) was inferred to be the rate control step of the reaction. That is, the total reaction rate depended on the hydrolysis rate of aluminum fluosilicate. Assumed that both Eq. (1) and Eq. (2) were first-order reactions, the following Eqs. (4)-(5) can be deduced ${ }^{23}$ :

$-\frac{d C_{H_{2} S i F_{6}}}{d t}=k_{1} \cdot C_{H_{2} S i F_{6}}$

$\frac{d C_{A l_{2}\left(S_{i} F_{6}\right)_{3}}}{d t}=\frac{1}{3} \cdot k_{1} \cdot C_{H_{2} S i F_{6}}-k_{2} \cdot C_{A l_{2}\left(S i F_{6}\right)_{3}}$

The boundary conditions of Eqs. (4)-(5) were: $t=0, C_{H_{2} S i F_{6}}=C_{H_{2} S i F_{6}}^{0}$

The solution to the system of Eqs. (4)-(5):

$C_{\mathrm{H}_{2} \mathrm{SiF}_{6}}=C_{\mathrm{H}_{2} S \mathrm{SF}_{6}}^{0} \cdot e^{-k_{1} \cdot t}$

$C_{A l_{2}\left(S i F_{6}\right)_{3}}=\frac{1}{3} \cdot \frac{k_{1} \cdot C_{H_{2} S i F_{6}}^{0}}{k_{1}-k_{2}} \cdot\left(e^{-k_{2} \cdot t}-e^{-k_{1} \cdot t}\right)$

$m$ and $q$ were defined as:

$m=\frac{k_{2}}{k_{1}}, q=m \cdot C_{H_{2} S_{i F}}^{0}{ }^{(1-m)}$

Plug $m$ and $q$ into the Eqs. (6)-(7):

$V=\frac{d C_{A l_{2}\left(S F_{6}\right)_{3}}}{d t}=\frac{1}{3} \cdot \frac{k_{1}^{2}}{k_{1}-k_{2}} \cdot C_{H_{2} S i F_{6}} \cdot\left(1-q \cdot C_{H_{2} S i F_{6}}{ }^{m-1}\right)$
$V=\frac{1}{3} \cdot\left(-\frac{d C_{H_{2} S F_{6}}}{d t}\right)=\frac{1}{3} \cdot \frac{k_{1}^{2}}{k_{1}-k_{2}} \cdot C_{H_{2} S i F_{6}} \cdot\left(1-q \cdot C_{H_{2} S F_{6}}{ }^{m-1}\right)$

Eq. (8) and Eq. (9) were the rate equations for the intrinsic reaction, where $k_{1}, k_{2}, q$ and $m$ were temperature-dependent functions.

\section{Macroscopic reaction kinetics}

Considering that aluminum hydroxide was a dense flake reactant, the uncreated-core model was adopted in this work. According to the uncreated-core model of kinetic theory, the reaction process of aluminum hydroxide and fluosilicic acid was composed of the following steps. (1) Fluosilicic acid diffused from the solution body through the liquid membrane to the reactant surface. (2) Fluosilicic acid diffused from the silica product layer on the outer surface of aluminum hydroxide to the unreacted aluminum hydroxide surface layer. (3) Fluosilicic acid was neutralized and hydrolyzed on the surface of unreacted aluminum hydroxide. (4) The liquid product aluminum fluoride diffused with water through the silica product layer to the outer surface of the reaction material. (5) The liquid product aluminum fluoride diffused with water through the liquid film from the outer surface of the reaction to the solution body. This process can be divided into external diffusion control, internal diffusion control and interfacial reaction-diffusion control. Since the concentration of fluosilicic acid in this experiment changes obviously, the classical simplified formula was not adopted. Due to the high mixing speed in this experiment, external diffusion control was not considered in this work. Aluminum hydroxide was assumed to be a granular reactant of equivalent diameter, formulas controlled by interfacial reaction and by internal diffusion would be derived below.

In the process of interface reaction control, the concentration of fluosilicic acid in the surface layer of unreacted aluminum hydroxide was equal to the concentration of the main body in the solution. The macroscopic reaction 
rate equation of the reactant fluosilicic acid and aluminum hydroxide was as Eq. (10) follows:

$-\frac{d n_{H_{2} S i F_{6}}}{d t}=12 \cdot \pi \cdot R_{c}{ }^{2} \cdot K_{s} \cdot C_{H_{2} S F_{6}} \cdot\left(1-q \cdot C_{H_{2} S F_{6}}{ }^{m-1}\right)$

$R_{c}$ was defined as the equivalent radius of unreacted aluminum hydroxide in the Eq. (10), and $K_{s}$ was defined as follows:

$K_{S}=\frac{k_{1}^{2}}{4 \cdot \pi \cdot R_{c}^{2} \cdot\left(k_{1}-k_{2}\right)}$

The stoichiometric relationship between aluminum hydroxide and fluosilicic acid can be obtained as follows:

$-\frac{d n_{\mathrm{H}_{2} \mathrm{SiF}}}{d t}=-\frac{1}{2} \cdot \frac{d n_{\mathrm{Al}(\mathrm{OH})_{3}}}{d t}=-\frac{2 \pi \cdot R_{c}^{2} \cdot \rho_{\mathrm{Al}(\mathrm{OH})_{3}}}{M_{A l(\mathrm{OH})_{3}}} \cdot \frac{d R_{c}}{d t}$

$\varrho$ was defined as the density of aluminum hydroxide, $M$ was defined as the relative molecular mass of aluminum hydroxide in the Eq. (11).

$-\frac{d R}{d t}=6 \cdot M_{A l(\mathrm{OH})_{3}} \cdot K_{s} \cdot C_{\mathrm{H}_{2} \mathrm{SiF}_{6}} \cdot\left(1-q \cdot C_{\mathrm{H}_{2} \mathrm{SiF}_{6}}{ }^{m-1}\right)$

The boundary condition of Eq. (11) was:

$t=0, C_{H_{2} S i F_{6}}=C_{H_{2} S i F_{6}}^{0}, R_{c}=R_{s}$

$R_{s}$ was defined as the outer surface equivalent radius of the particle containing the reactant aluminum hydroxide and silicon dioxide product layer.

Solution to the system of Eq. (6) and Eq. (12):

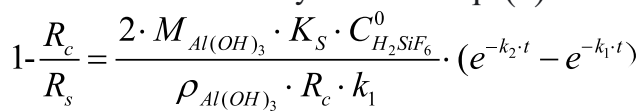

$\alpha$ was defined as follows:

$\alpha=1-\left(\frac{R_{c}}{R_{s}}\right)^{3}$

$1-(1-\alpha)^{\frac{1}{3}}=\frac{2 \cdot M_{A l(\mathrm{OH})_{3}} \cdot K_{S} \cdot C_{\mathrm{H}_{2} \mathrm{SiF}_{6}}^{0}}{\rho_{\mathrm{Al}(\mathrm{OH})_{3}} \cdot R_{c} \cdot k_{1}} \cdot\left(e^{-k_{2} \cdot t}-e^{-k_{1} \cdot t}\right)$

The boundary condition of Eq. (14) was:

$\alpha=1, t=t_{\text {finish }}$

$t_{\text {finish }}$ was defined as the reaction time of the complete reaction.

$e^{-k_{2} \cdot t_{\text {frish }}}-e^{-k_{1} \cdot t_{\text {finish }}}=\frac{\rho_{\mathrm{Al}(\mathrm{OH})_{3}} \cdot R_{c} \cdot k_{1}}{2 \cdot M_{A l(\mathrm{OH})_{3}} \cdot K_{S} \cdot C_{\mathrm{H}_{2} S F_{6}}^{0}}$

$e^{-k_{1} \cdot t_{\text {fnish }}} \cdot\left(e^{\left(k_{1}-k_{2}\right) \cdot t_{\text {finish }}}-1\right)=\frac{\rho_{A l(\mathrm{OH})_{3}} \cdot R_{c} \cdot k_{1}}{2 \cdot M_{A l(\mathrm{OH})_{3}} \cdot K_{S} \cdot C_{\mathrm{H}_{2} S i F_{6}}^{0}}$

From the mechanism described earlier, $k_{1}$ is much larger than $k_{2}$.

$k_{1}>>k_{2}, k_{1}-k_{2} \approx k_{1}$

$t_{\text {finish }}=\frac{1}{k_{1}} \cdot \ln \left(1-\frac{\rho_{\mathrm{Al}(\mathrm{OH})_{3}} \cdot R_{c} \cdot k_{1}}{2 \cdot M_{\mathrm{Al}(\mathrm{OH})_{3}} \cdot K_{S} \cdot C_{\mathrm{H}_{2} S i F_{6}}^{0}}\right)^{-1}$

Solution to the system of Eq. (14) and Eq. (17):

$1-(1-\alpha)^{\frac{1}{3}}=\frac{e^{-k_{2} \cdot t}-e^{-k_{1} \cdot t}}{1-e^{-k_{1} \cdot t_{\text {finish }}}} \stackrel{k_{1}>>k_{2}}{\longrightarrow} \frac{1-e^{-k_{1} \cdot t}}{1-e^{-k_{1} \cdot t_{\text {finish }}}}$

Eq. (18) was the macroscopical reaction kinetics equation controlled by the interface reaction of fluosilicic acid and aluminum hydroxide.
In the process of internal diffusion control, the diffusion rate of the reactant fluosilicic acid through the silica product layer was the total speed of the macroscopic reaction process. According to fick diffusion law, the diffusion rate of fluosilicic acid through the silica product layer was as Eq. (19) follows:

$-\frac{d n_{H_{2} S i F_{6}}}{d t}=4 \cdot \pi \cdot R^{2} \cdot D_{e} \cdot\left(\frac{d C_{H_{2} S i F_{6}}}{d R}\right)_{R=R_{c}}$

$D_{e}$ was defined as the diffusion coefficient of fluosilicic acid through the silica product layer in Eq. (19).

Eq. (20) can be obtained from material balance:

$\frac{d_{\mathrm{H}_{2} \mathrm{SiF}_{6}}^{2}}{d R^{2}}+\frac{2}{R} \cdot \frac{d C_{\mathrm{H}_{2} \mathrm{SiF}_{6}}}{d R}=0$

The boundary condition of Eq. (20) was:

$R=R_{c}, C_{\mathrm{H}_{2} \mathrm{SiF}_{6}}=0 ; R=R_{s}, C_{\mathrm{H}_{2} \mathrm{SiF}_{6}}=C_{\mathrm{H}_{2} \mathrm{SiF}_{6}}^{s}$

$C_{H_{2} S_{i} F_{6}}^{s}$ was defined as the concentration of fluosilicic acid on the particle surface.

Solution to the system of Eq. (20):

$C_{H_{2} S_{i} F_{6}}=C_{H_{2} S_{i} F_{6}}^{s} \cdot \frac{1-\frac{R_{c}}{R}}{1-\frac{R_{c}}{R_{s}}}$

Put Eq. (21) into Eq. (19):

$-\frac{d n_{H_{2} S_{i F}}}{d t}=4 \cdot \pi \cdot R \cdot D_{e} \cdot \frac{C_{H_{2} S i F_{6}}^{s}}{1-\frac{R_{c}}{R_{s}}}$

Put Eq. (11) into Eq. (21):

$-\frac{d R_{c}}{d t}=\frac{2 \cdot D_{e} \cdot R_{s} \cdot M_{A l(\mathrm{OH})_{3}} \cdot C_{\mathrm{H}_{2} \mathrm{SiF}_{6}}^{s}}{\rho_{\mathrm{Al}(\mathrm{OH})_{3}} \cdot\left(R_{s}-R_{c}\right)}$

Considering the effect of high stirring speed on external diffusion, the concentration of fluosilicic acid on the outer surface of the particle was approximately equal to the concentration of fluosilicic acid on the main body of the solution:

$C_{H_{2} S i F_{6}}^{s} \approx C_{H_{2} S_{i F}}=C_{H_{2} S_{i F_{6}}}^{0} \cdot e^{-k_{1} \cdot t}$

The boundary condition of Eq. (23) was:

$t=0, R_{c}=R_{s}$

Integrate both sides of Eq. (23):

$1+2 \cdot\left(\frac{R_{c}}{R_{s}}\right)^{3}-3 \cdot\left(\frac{R_{c}}{R_{s}}\right)^{2}=\frac{12 \cdot D_{e} \cdot M_{A l(\mathrm{OH})_{3}} \cdot C_{\mathrm{H}_{2} \mathrm{SiF}_{6}}^{0}}{R_{s}{ }^{2} \cdot \rho_{\mathrm{Al}(\mathrm{OH})_{3}} \cdot k_{1}}\left(1-e^{-k_{1} \cdot t}\right)$

The boundary condition of Eq. (24) was:

$\alpha=1, t=t_{\text {finish }}$

$t_{\text {finish }}=\frac{1}{k_{1}} \ln \left(1-\frac{R_{s}^{2} \cdot \rho_{\mathrm{Al}(\mathrm{OH})_{3}} \cdot k_{1}}{12 \cdot D_{e} \cdot M_{A l(\mathrm{OH})_{3}} \cdot C_{\mathrm{H}_{2} \mathrm{Sil}}^{0}}\right)$

Solution to the system of Eq. (24) and Eq. (25):

$1+2 \cdot(1-\alpha)-3 \cdot(1-\alpha)^{\frac{2}{3}}=\frac{1-e^{-k_{1} \cdot t}}{1-e^{-k_{1} \cdot t_{\text {frish }}}}$

Eq. (26) was the macroscopical reaction kinetics equation controlled by the internal diffusion of fluosilicic acid and aluminum hydroxide. 


\section{Experimental data fitting}

From the above formula derivation, if the reaction is controlled by interfacial reaction, the plot of $1-(1-\alpha)^{\frac{1}{3}}$ with time is an exponential decay 1 relationship. Similarly, if the reaction is controlled by internal diffusion, the plot of $1+2 \cdot(1-\alpha)-3 \cdot(1-\alpha)^{\frac{2}{3}}$ with time is an exponential decay 1 relationship. In this work, we adopted Eq. (18) and Eq. (26) to evaluate the contribution of interfacial reaction and internal diffusion to the reaction.

It can be observed from Figure 3 that with the rise of temperature, the overall trend of mass concentration of silica increased at the same time, which can be explained by the increase of temperature and the increase of reaction rate. Considering that the above equations were based on the concentration of fluosilicic acid, the mass concentration of silica was converted into the concentration of fluosilicic acid according to the following Eq. (27) and Eq. (28). As can be seen from Figure 4, with the rise of temperature, the overall trend of the concentration of fluosilicic acid decreased in the same time.

$C_{\mathrm{SiO}_{2}}^{M}=\frac{\frac{1}{2} \cdot n_{\mathrm{Al}(\mathrm{OH})_{3}} \cdot M_{\mathrm{SiO}_{2}} \cdot \alpha}{\frac{1}{2} \cdot n_{\mathrm{Al}(\mathrm{OH})_{3}} \cdot M_{\mathrm{SiO}_{2}} \cdot \alpha+n_{\mathrm{Al}(\mathrm{OH})_{3}} \cdot M_{\mathrm{Al}(\mathrm{OH})_{3}} \cdot(1-\alpha)}$

$C_{\mathrm{H}_{2} \mathrm{SiF}_{6}}=C_{\mathrm{H}_{2} \mathrm{SiF} F_{6}}^{0}-\frac{n_{\mathrm{Al}(\mathrm{OH})_{3}} \cdot \alpha \cdot \rho_{L}}{2 \cdot m_{L}}$

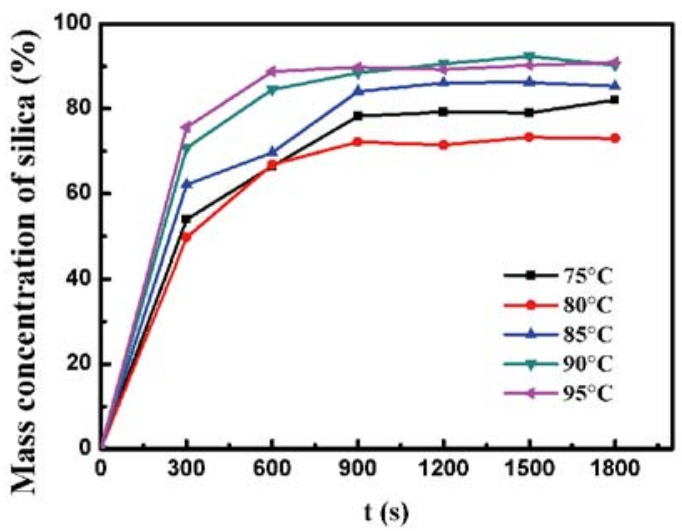

Figure 3. Variation of silica content in products at different temperatures

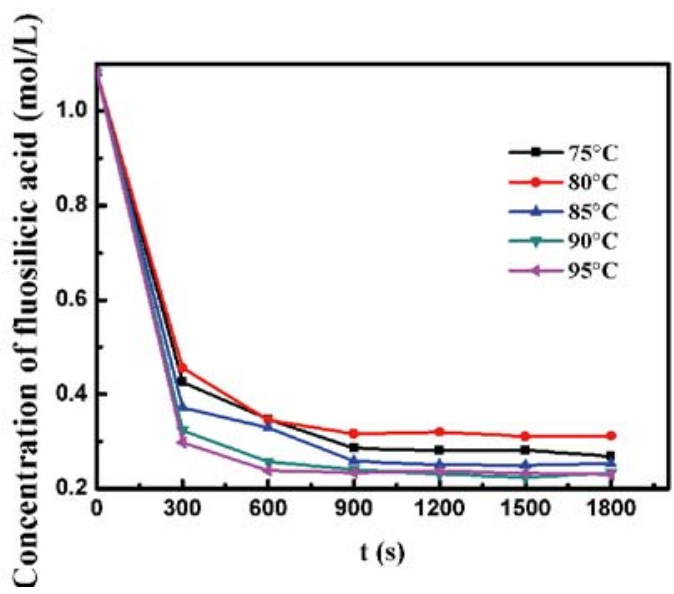

Figure 4. Variation of fluosilicic acid concentration at different temperatures
$n_{\mathrm{Al}(\mathrm{OH})_{3}}$ was defined as the amount of aluminum hydroxide, $M_{\mathrm{SiO}_{2}}$ was defined as the relative molecular mass of silicon dioxide and $M_{A l(O H)_{3}}$ was defined as the relative molecular mass of aluminum hydroxide in Eq. (27). $\rho_{L}$ was defined as the density of the liquid and $m_{L}$ was defined as the mass of liquid in Eq. (28).

According to the evaluation, the fitting degree controlled by internal diffusion and the fitting degree controlled by interface reaction was very close to 1 . The relevant fitting degrees were marked in Fig. 5 and Figure 6. It can be inferred that the reaction between fluosilicic acid and aluminum hydroxide was controlled by internal diffusion and interfacial reaction. When the reaction started, the reaction was mainly controlled by the interface reaction due to the product layer silica did not accumulate. When the thickness of silica in the product layer accumulated to a certain thickness, the internal diffusion resistance of fluosilicic acid increased, and the reaction changed from interfacial reaction control to internal diffusion control.

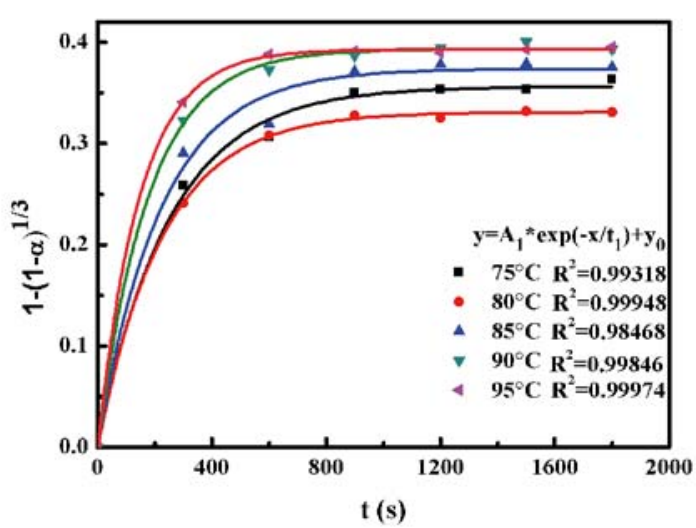

Figure 5. Relationship plots of $1-(1-\mathrm{a}) \wedge(1 / 3)$ and time at different temperatures

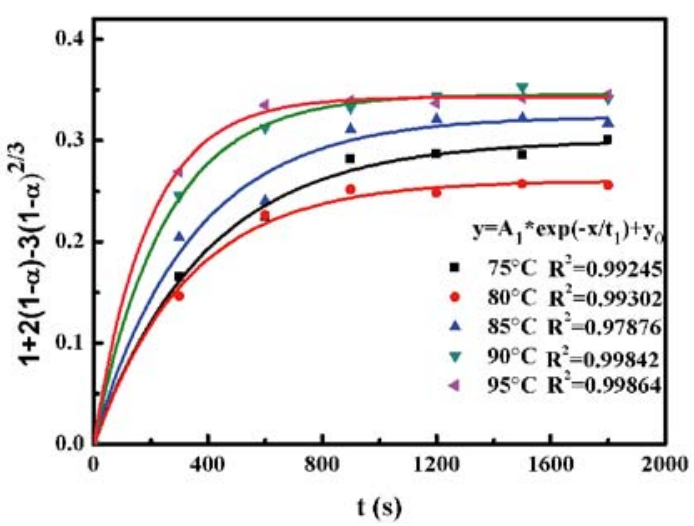

Figure 6. Relationship plots of $1+2(1-a)-3(1-a) \wedge(2 / 3)$ and time at different temperatures

It can be seen from Figure 7 that the relationship between $-\frac{d C_{\mathrm{H}_{2} \mathrm{SiF}_{6}}}{d t}$ and $\mathrm{C}_{\mathrm{H}_{2} \mathrm{SiF}_{6}}$ conformed to a linear relationship. Combined with Eq. (8), it can be inferred that $\mathrm{m} \approx 0$ which conformed to the previous assumption that $\mathrm{k}_{1}>>k_{2}$, and the apparent reaction rate constant at various temperatures can be obtained based on this 


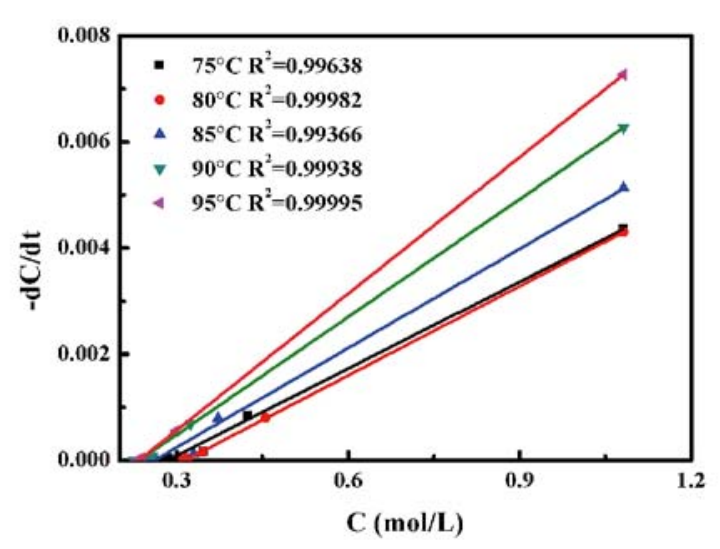

Figure 7. Relationship plots of $-\mathrm{dC} / \mathrm{dt}$ and fluosilicic acid concentration at different temperatures

figure. It was also proved that the apparent reaction order of this reaction was 1 from Figure 7.

As shown in Figure 8, the linear fitting degree of this curve can be observed from the arienius curve of the reaction between aluminum hydroxide and fluosilicic acid as 0.98332 , and the apparent activation energy $E_{a}$ can be obtained as $30.8623 \mathrm{~kJ} / \mathrm{mol}$.

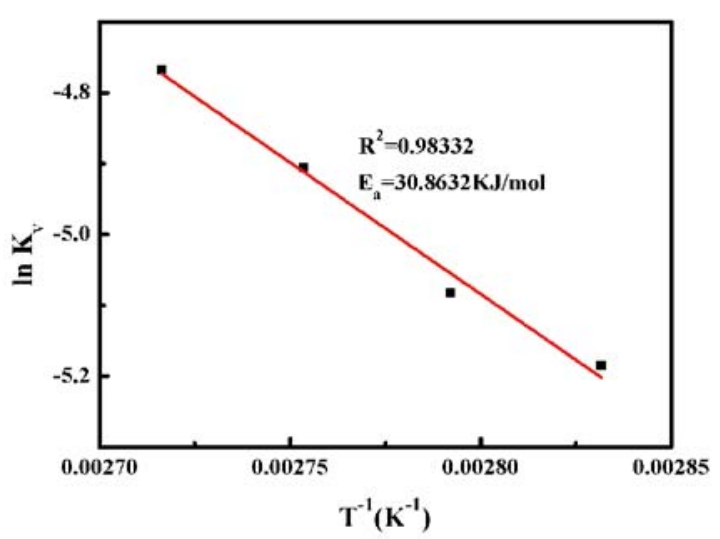

Figure 8. Arrhenius plot for the reaction of aluminum hydroxide with fluosilicic acid

\section{CONCLUSIONS}

The kinetic mechanism of the reaction between aluminum hydroxide and fluosilicic acid was analyzed by measuring the yield of silica at different temperatures, and the following conclusions were drawn:

(1) The kinetic results showed that the uncreated-core model was suitable for the reaction of fluosilicic acid with aluminum hydroxide, which was controlled by internal diffusion and interfacial reaction. The kinetic parameters of the reaction, the apparent reaction series $\mathrm{n}=1$, the apparent activation energy $E_{a}=30.8623 \mathrm{~kJ} / \mathrm{mol}$.

(2) In view of the obvious changes in the concentration of fluosilicic acid, the kinetic equation different from the traditional uncreated-core model was adopted. Combining with the SEM diagram of the reaction product of fluosilicic acid and aluminum hydroxide, the reaction process of fluosilicic acid and aluminum hydroxide conformed to the uncreated-core model composed of three steps: diffusion, interfacial reaction and internal diffusion.
(3) This dynamic mechanism directly explained that silica products contained aluminum hydroxide impurities, and internal diffusion and interfacial reaction were the control steps of this reaction. It could be considered to improve the purity of silica by improving the effect of internal diffusion and interfacial reaction. This work has certain guiding significance to the direct method of aluminum fluoride by using fluosilicic acid.

\section{ACKNOWLEDGMENTS}

The authors gratefully acknowledge financial support from Chinese National Key Research and Development Project (2018YFC1900203-03), Chinese National Natural Science Foundation (21776181), Sichuan University innovation spark project (2018SCUH0012) and Special Project of Building World-class Universities (2030704401004). Science and Technology Plan Project of Sichuan Province (2021YFG0285).

\section{NOMENCLATURE}

$\mathrm{C}_{\mathrm{H}_{2} \mathrm{SiF}_{6}}$ - molarity of fluosilicic acid in solution, mol/L; $C_{A l_{2}\left(S_{i} F_{6}\right)_{3}}$ - molarity of aluminum fluosilicate in solution, $\mathrm{mol} / \mathrm{L}$;

$\mathrm{k}_{1}$ - reaction rate constant of Eq. (1), $\mathrm{s}^{-1}$;

$\mathrm{k}_{2}$ - reaction rate constant of Eq. (2), $\mathrm{s}^{-1}$;

$\mathrm{k}_{3}$ - reaction rate constant of Eq. (3), $\mathrm{s}^{-1}$;

$\mathrm{t}$ - reaction time, s;

$\mathrm{C}_{\mathrm{H}_{2} \mathrm{SiF}_{6}}^{0}$ - initial molality of fluosilicic acid in solution, $\mathrm{mol} / \mathrm{L}$;

$\mathrm{R}_{\mathrm{c}}$ - equivalent radius of unreacted aluminum hydroxide, $\mathrm{m}$;

$\mathrm{Q}$ - density of aluminum hydroxide, $\mathrm{g} / \mathrm{L}$;

$\mathrm{M}$ - relative molecular mass of aluminum hydroxide, $\mathrm{g} / \mathrm{mol}$;

$\mathrm{R}_{\mathrm{s}}$ - outer surface equivalent radius of the particle containing the reactant aluminum hydroxide and silicon dioxide product layer, $\mathrm{m}$;

$\alpha$ - reaction conversion rate;

$\mathrm{t}_{\text {finish }}$ - reaction time of the complete reaction, $\mathrm{s}$;

$\mathrm{D}_{\mathrm{e}}$ - diffusion coefficient of fluosilicic acid through silica product layer;

$C_{H_{2} S i F_{6}}^{s}$ - molarity of fluosilicic acid on the particle surface, $\mathrm{mol} / \mathrm{L}$;

$n_{A l(O H)_{3}}$ - amount of aluminum hydroxide, mol;

$M_{\mathrm{SiO}_{2}}$ - relative molecular mass of silicon dioxide, $\mathrm{g} / \mathrm{mol}$;

$M_{A l(\mathrm{OH})_{3}}$ - relative molecular mass of aluminum hydro-

xide, $\mathrm{g} / \mathrm{mol}$;

$\rho_{L}-$ density of liquid, $\mathrm{g} / \mathrm{L}$;

$m_{L}-$ mass of liquid, $\mathrm{g}$.

\section{LITERATURE CITED}

1. Zhang, J., Zhu, L., Yang, G. \& Xie, F. (2007). The study of the source of fluorine and its influence on environment in phosphorite of Zhijin in Guizhou, 17 October 2007 (pp. 538-540). Qingdao, China: International Conference on Mine Hazards Prevention and Control.

2. Will, R.K. (2016). The Benefits of Isolating \& Utilizing Fluorine from Phosphate Operations, 18-20 March 2016 (pp. 267-72). Marrakech, Morocco: 3rd International Symposium on Innovation and Technology in the Phosphate Industry.

3. Petlin, IV \& Lesnikova, M.S. (2017). Ways of processing and recycling of fluorine-containing waste of aluminum industry. 
Izvestiya Vysshikh Uchebnykh Zavedenii Khimiya I Khimicheskaya Tekhnologiya. 60(4), 108-113. DOI: 10.6060/tcct.2017604.5352.

4. Hou, J., Shi, D., Wang, Z., Gao, B., Shi, Z. \& Hu, X. (2017). Influence of Additives on Bath Analysis in Aluminum Electrolysis. JOM. 69(10), 2057-064. DOI: 10.1007/s11837017-2482-8

5. Murashkevich, A.N., Vorobev, N.I., Pechkovskii, V.V., Sechko, S.I. \& Pimenov, V.V., (1986). Production of sodium metasilicate from silica-gel, aluminum fluoride production wastes. Khimicheskaya Promyshlennost. 11, 700.

6. Dreveton, A. (2012). Manufacture of Aluminium Fluoride of High Density and Anhydrous Hydrofluoric Acid from Fluosilicic Acid, 9-13 May 2012 (pp. 255-265). Marrakesh, Morocco: 1st International Symposium on Innovation and Technology in the Phosphate Industry.

7. Korobitsyn, A.S., Smirnov, A.V. \& Kondakov, V.P. (1980). Improvement of technology of aluminum fluoride from hydrofluoric-acid production. Khimicheskaya Promyshlennost. 10, 605-606.

8. Elrashidi, M.A. \& Lindsay, W.L. (1986). Solubility of aluminum fluoride, fluorite, and fluorophlogopite minerals in soils. Soil. Sci. Soc. Am. J. 50(3), 594-598. DOI: 10.2136/sssa j1986.03615995005000030010x.

9. Vian, A., Brusi, J.M., Guardiola, E. \& Diago, A. (1984). Study of formation-decomposition of fluosilicate in a phosphoric-acid purification process. Revista Latinoamericana De Ingenieria Quimica Y Quimica Aplicada-Latin American J. Chem. Engin. Appl. Chem. 14(1), 95-102.

10. Long, B., Wang, Z., Zhang, Q., Ke, W. \& Ding, Y. (2018). Improved process to prepare high-purity anhydrous potassium fluoride from wet process phosphoric acid. Chem. Eng. Commun. 205(10), 1342-1350. DOI: 10.1080/00986445.2018.1450246.

11. Will, R.K. (2016). The Benefits of Isolating \& Utilizing Fluorine from Phosphate Operations, 18-20 May 2016 (pp. 267-272). Marrakech, Morocco: 3rd International Symposium on Innovation and Technology in the Phosphate Industry.

12. Krysztafkiewicz, A., Rager, B. \& Maik, M. (1996). Silica recovery from waste obtained in hydrofluoric acid and aluminum fluoride production from fluosilicic acid. J. Hazard Mater. 48(1-3), 31-49. DOI: 10.1016/0304-3894(95)00126-3.

13. Zeng, R. \& Ge, Y. (2019). US patent CN110316749-A. Washington, D.C.: U.S. Patent and Trademark Office.
14. Grobelny, M. (1977). Effect of reaction conditions on properties of silica obtained in reaction of fluorosilicic acid with aluminum hydroxide. Przem. Chem. 56(10), 533-536.

15. Martin, J.E., Wilcoxon, J.P., Schaefer, D. \& Odinek, J. (1990). Fast aggregation of colloidal silica. Phys. Rev. A. 41(8), 4379-4391. DOI: 10.1103/PhysRevA.41.4379.

16. Versteeg.Pm \& Thoonen, T.J. (1972). Aluminum fluoride from waste hydro-fluo-silicic acid. Abstracts Papers Amer. Chem. Society. 164, 24.

17. Bayat, M., Taeb, A. \& Rastegar, S. (2002). Investigation of the filtration rate of silica in aluminum fluoride production from silicic acid. Chem. Eng. Sci. 57(15), 2879-2884. DOI: 10.1016/S0009-2509(02)00216-6.

18. Bayat, M., Taeb, A. \& Rastegar, S. (2005). The contribution of molecular diffusion in silica coating and chemical reaction in the overall rate of reaction of aluminum hydroxide with fluosilicic acid. Iranian J. Chem. \& Chem. Engin-Internat. English Edition. 24(4), 15-24.

19. Huang, Y., Dou, Z., Zhang, T-a \& Liu, J. (2017). Leaching kinetics of rare earth elements and fluoride from mixed rare earth concentrate after roasting with calcium hydroxide and sodium hydroxide. Hydrometallurgy. 173, 15-21. DOI: 10.1016/j. hydromet.2017.07.004.

20. Lu, G., Zhang, T., Zhang, G., Zhang, W., Zhang, Y., Dou, Z., Wang, L., Wang, Y. \& Xie, G. (2019). Process and Kinetic Assessment of Vanadium Extraction from Vanadium Slag Using Calcification Roasting and Sodium Carbonate Leaching. JOM. 71(12), 4600-4607. DOI: 10.1007/s11837-019-03672-9.

21. Nie, S. (2014). Determination on silicon dioxide content in silica by potassium silicofluoride volumetric mthod. Ferro Alloys. 2, 53-56. Retrieved 2014, from the database of cnki on the world wide web: https://www.cnki.net.

22. Yi, C. (2004). Selection of fluorosilicic acid content analysis method. Phosphate \& Compound Fertilizer. 5, 65. Retrieved 2004, from the database of cnki on the world wide web: https://www.cnki.net.

23. Li, MQ. (1998). A/P wet aluminum fluoride production process analysis and simulation of desilication reaction kinetics. Phosphate \& Compound Fertilizer. 2, 12-18. Retrieved 1998, from the database of cnki on the world wide web: https:// www.cnki.net. 